\title{
Laboreal
}

Volume $14 \mathrm{~N}^{\circ} 1$ | 2018

$\mathrm{O}$ regresso ao emprego após um acidente de trabalho

\section{Um retorno a Gilbert Simondon e à sua obra inicial}

Volver sobre Gilbert Simondon y su libro inicial

Un retour à Gilbert Simondon et à son cuvre initiale

A return to Gilbert Simondon and to his initial work

\section{Jacques Leplat}

Tradutor. João Viana Jorge

\section{OpenEdition}

\section{Journals}

Edição electrónica

URL: http://journals.openedition.org/laboreal/541

DOI: $10.4000 /$ laboreal.541

ISSN: 1646-5237

\section{Editora}

Universidade do Porto

\section{Refêrencia eletrónica}

Jacques Leplat, « Um retorno a Gilbert Simondon e à sua obra inicial », Laboreal [Online], Volume 14 $N^{0} 1$ | 2018, posto online no dia 01 julho 2018, consultado o 24 setembro 2020. URL : http:// journals.openedition.org/laboreal/541 ; DOI : https://doi.org/10.4000/laboreal.541

Este documento foi criado de forma automática no dia 24 setembro 2020.

Laboreal está licenciado com uma Licença Creative Commons - Atribuição-NãoComercial 4.0 Internacional. 


\title{
Um retorno a Gilbert Simondon e à sua obra inicial
}

\author{
Volver sobre Gilbert Simondon y su libro inicial \\ Un retour à Gilbert Simondon et à son cuvre initiale \\ A return to Gilbert Simondon and to his initial work
}

Jacques Leplat

Tradução : João Viana Jorge

\section{REFERÊNCIA}

Comentário ao texto de Simondon, G. (1969). Introduction. In G. Simondon. Du mode d'existence des objets techniques (pp. 9-16). Paris: Aubier.

\section{NOTA DO EDITOR}

http://dx.doi.org/10.15667/laborealxiv0118jl

Manuscrito recebido em: janeiro/2018

Aceite após peritagem: fevereiro/2018

Agradeço muito vivamente a Marianne Lacomblez e a Régis Ouvrier Bonnaz pela releitura que fizeram do meu texto inicial para o pôr de acordo com as normas da revista e facilitar a sua leitura a futuros leitores.

1 Não surpreenderá, ninguém que se interesse pela história do trabalho, ver figurar o nome de Simondon num texto da revista Laboreal geralmente orientada para as questões relacionadas com o domínio da psicologia do trabalho e da ergonomia. Como escreve este autor na introdução da obra «Du mode d'existence des objects techniques» [1], 'o homem é o organizador permanente de uma sociedade dos objetos técnicos que têm necessidade dele como os músicos necessitam de um maestro' (p. 11). A história da ergonomia 
da atividade como a da psicologia do trabalho acarreta numerosas ilustrações desta declaração desde os primeiros tempos da afirmação da abordagem que lhes é comum (Ombredane e Faverge,1955; Leplat e Cuny, 1977; Montmoulin , 1984; Wisner, 1985; Rabardel, 1995). O nome de Gilbert Simondon está associado aos objetos técnicos. Mas não se deve reduzir o livro de Simondon a este único aspeto e constata-se desde a leitura das primeiras páginas dessa obra que as suas análises se desenvolvem num quadro mais alargado.

\section{Gilbert Simondon, um autor primordial, original, mas tardiamente apreciado}

2 Previamente a este comentário lembrarei que Simondon iniciou a sua carreira na Universidade de Poitiers que a seguir abandonou pela da Sorbonne. Como se pode constatar na sua bibliografia, tal como a retomada na obra, é autor de grande número de publicações sobre diversos temas, ainda que o seu interesse pelas questões tocantes às relações entre o homem e o trabalho fosse preponderante, tendo-se isso manifestado de maneiras diversas: pelo estabelecimento de relações com os docentes, pelas conferências, pelas participações em júris de teses e em numerosos congressos.

3 Tive a sorte de o conhecer no início da sua carreira e, depois, de o encontrar frequentemente no seu Laboratório no Instituto de Psicologia da rua Serpente (Sorbonne) e nunca vou esquecer as visitas comentadas que me fez fazer à sua sala de experimentação na qual se encontrava um certo número de objetos que figuram na tabela no início do livro aqui discutido. Cada um desses objetos, extremamente variados, tinha uma história que ele gostava de contar, pronto a responder a todas as questões.

Gilbert Simondon (1929-1989) é pois um autor primordial e original no campo das pesquisas respeitantes às relações entre a cultura e a técnica. A presente obra ocupa nisso um lugar central, reconhecida pela riqueza da análise proposta mas também pelas numerosas pistas de pesquisas aparentadas que aí apresenta. $O$ interesse que lhe dedicaram é aliás hoje renovado no quadro de numerosos projetos. E assim, alguns fazem referência a uma «redescoberta da obra de Simondon». É verdade que, se a sua originalidade e o seu valor foram muito cedo reconhecidos pelos seus pares, a obra não conquistou de imediato grande público, sem dúvida desencorajado por passagens do livro por vezes muito técnicas. Foram necessários anos a fio para que essa contribuição encontrasse por fim a audiência que merece, provavelmente favorecida por alguns grandes leitores que constituem 'a base com a qual Simondon elaborou, através do diálogo direto com a epistemologia de Canguilhem, a fenomenologia de Maurice Merleau-Ponty e a cibernética de Wienner, a originalidade de um pensamento que autoriza uma perspetiva que pode dizer-se ecológica e cuja força deve hoje ser necessariamente considerada' (Bardin, 2014, p. 26).

5 A título de exemplo dos esforços empreendidos para fazer justiça, há já um quarto de século, à obra de G. Simondon, pode lembrar-se a declaração, em 1992, de Hubert Curien, antigo diretor doCentre National de la Recherche Scientifique (CNRS) e do Centre National d'Études Spaciales (CNES) por altura dum colóquio organizado pelo Colégio Internacional de Filosofia: 'Estou particularmente feliz por apresentar um encontro que procura analisar e rememorar o pensamento de Gilbert Simondon. Esse pensamento tão 
necessário, tão fecundo para o nosso tempo, tão exemplarmente atual, deve ser retirado dum injusto esquecimento (...) G. S. era um homem de grande cultura científica, particularmente em física e em biologia (...). Era também um investigador exemplar do devir cultural, das realidades psicológicas e sociais: não recortava artificialmente o mundo a partir da tão lamentável separação entre as ciências da natureza por um lado e ciências do espírito, por outro.'

\section{Génese do objeto técnico: o processo de concretização}

6 A análise exaustiva do livro ultrapassaria a finalidade habitual desta rubrica da revista. Privilegiaremos portanto aqui, relacionado com a introdução, o que retivemos do primeiro capítulo e da conclusão da obra.

7 Esse primeiro capítulo faz na realidade o relanço da introdução retomando os temas frequentemente desenvolvidos em pesquisas relativas a situações de trabalho. $O$ autor escolhe aí o motor de automóvel como exemplo de objeto técnico. Sublinha:

8 No motor antigo, cada elemento intervém num dado momento do ciclo e depois é suposto não mais agir sobre os outros elementos enquanto no motor atual cada peça importante é de tal modo ligada às outras por recíprocas trocas de energia que não pode ser outra que não ela. Pode dizer-se que o motor atual é um motor concretoenquanto o motor antigo é um motor abstrato. A essência da concretização do objeto técnico é a organização de subconjuntos funcionais no funcionamento total ( $\mathrm{p}$. 34, tradução livre).

9 Nesta lógica Simondon estuda então sucessivamente: a evolução técnica, o ritmo do progresso técnico $e$ as linhagens técnicas. Insiste muito sobre as modalidades e as consequências da concretização dos objetos técnicos bem como sobre a sua exploração. Segundo ele o artesanato recorre ao estado primitivo da evolução dos objetos técnicos, quer dizer ao estado abstrato e a indústria explora o estado concreto. As modalidades desta passagem são examinadas em detalhe e discutidas a propósito de exemplos definidos que permitem discernir estilos de evolução. Nota portanto que a construção dum objeto técnico determinado pode tornar-se industrial quando esse objeto se torna concreto, a saber: quando o conhecimento subjacente à instrução construtiva e o do olhar científico são análogos.

Afirma igualmente:

11 (...) existem dois tipos de aperfeiçoamento (...) os aperfeiçoamento menores prejudicam os aperfeiçoamentos maiores, porque podem mascarar, verdadeiras imperfeições dum objeto técnico com artifícios não essenciais, incompletamente integrados no funcionamento do conjunto, os verdadeiros antagonismos... (...) As etapas reais do aperfeiçoamento técnico fazem-se por mutações, mas por mutações orientadas (p. $39 \mathrm{e}$ 40, tradução livre).

E acrescenta mais adiante aquando de outro exemplo, o do díodo:

13 A concretização dá ao objeto técnico um lugar intermediário entre o objeto natural e a representação científica. $\mathrm{O}$ objeto técnico abstrato, quer dizer primitivo, está muito longe de constituir um sistema natural, físico. É a tradução física de um sistema intelectual (...) Pelo contrário, o objeto técnico concreto, quer dizer evoluído, aproxima- 
se do modo de existência dos objetos naturais, tende para a coerência interna, para o fecho do sistema de causas e efeitos que se exercem circularmente no interior do seu entorno (...). Esse objeto, evoluindo, perde o seu caracter artificial: a artificialidade essencial de um objeto reside no facto de que o homem deve intervir para manter a sua existência protegendo-o do mundo natural dando-lhe um estatuto de existência aparte... (p. 46 e 47, tradução livre).

\section{Objeto técnico e trabalho}

Compreende-se a importância da contribuição de Simondon por qualquer das reflexões sobre as relações entre o objeto técnico e o trabalho humano. Aliás, no primeiro parágrafo da conclusão daquele livro, escreve:

5 Até hoje a realidade do objeto técnico passou a segundo plano, atrás da do trabalho humano. O objeto técnico foi apreendido através do trabalho humano, pensado e julgado como instrumento, adjuvante ou produto do trabalho. Ora, seria necessário, em favor do próprio homem, poder operar uma reviravolta que permitisse o aparecimento direto ao que há de humano no objeto técnico, sem passar pela relação de trabalho. É o trabalho que deve ser (re)conhecido como fase da tecnicidade porque é a tecnicidade que é o conjunto de que o trabalho é uma parte e não o inverso (p.241, tradução livre).

Estas questões serão retomadas e aprofundadas ulteriormente. Podem ver-se mais explicitadas numa obra que agrupa textos de Simondon (2014). Todavia já aqui nos diz:

(...) o trabalho pode ser tomado como aspeto da operação técnica, que não se reduz ao trabalho. Só há trabalho quando o homem doa o seu organismo como portador de utensílios, quer dizer quando o homem deva acompanhar, pela atividade do seu organismo, da sua unidade psicossomática, o desenrolar, etapa por etapa, da relação homem-natureza. o trabalho é a atividade pela qual o homem realiza nele próprio a mediação entre a espécie humana e a natureza; dizemos que neste caso o homem opera como portador de ferramentas porque nesta atividade age sobre a natureza e segue, passo a passo, gesto a gesto, essa ação. Trata-se de trabalho quando o homem não pode confiar ao objeto técnico a função de mediação entre a espécie e a natureza, e deve cumprir ele próprio, com o seu corpo, o seu pensamento, a sua ação, essa função de relação. O homem empresta então a sua própria atividade de ser vivo para organizar essa operação; é nisso que é portador de ferramentas. Em contrapartida quando o objeto técnico é concretizado o misto de natureza e homem é constituído ao nível desse objeto; a operação sobre o ser técnico não é exatamente um trabalho. Com efeito, no trabalho o homem coincide com uma realidade que não é humana, verga-se a uma realidade, escorrega de algum modo entre a realidade natural e a intenção humana; o homem no trabalho modela a matéria segundo uma dada forma; alcança essa forma que é uma intenção de resultado, uma pré determinação do que é preciso obter no termo da obra segundo as necessidade pré-existentes. Essa forma-intenção não faz parte da matéria sobre a qual o trabalho incide; exprime uma utilidade para ou uma necessidade do homem mas não sai da natureza. A atividade de trabalho é o que estabelece a ligação entre a matéria natural e a forma e é de proveniência humana; o trabalho é uma atividade que chega a fazer coincidir, a tornar sinérgicas, duas realidades tão heterogéneas como a matéria e a forma (p. 242, tradução livre). 


\section{Do modo de existência dos objetos técnicos aos resultados do seu funcionamento}

Enfim, lamentaríamos não evocar nesta breve apresentação a perspetiva de pesquisa que Simondon traça indicando quanto o estudo do modo de existência dos objetos técnicos deveria ser prologado pelo dos resultados do seu funcionamento e das atitudes do homem face a esses objetos técnicos:

A atividade técnica ao edificar o mundo dos objetos técnicos e generalizar a mediação objetiva entre o homem e a natureza, prende o homem à natureza por um elo muito mais rico e melhor definido do que o da reação específica do trabalho coletivo. Uma conversibilidade do humano em natural e do natural em humano instituiu-se através do esquematismo técnico. (...) A perceção corresponde à colocação em questão direta do homem vivendo pelo mundo natural. A ciência corresponde à mesma colocação em questão... A ciência corresponde à mesma colocação em questão através do universo técnico. Para o trabalho sem obstáculo a sensação é suficiente; a perceção corresponde ao problema que surge ao nível do trabalho. Em contrapartida, enquanto as técnicas resultam, o pensamento científico não é convidado a nascer. Quando as técnicas falham a ciência está próxima. A ciência corresponde a uma problemática formulada ao nível das técnicas e que não pode encontrar solução ao nível das técnicas. A técnica intervém entre perceção e ciência para provocar uma mudança de nível; fornece esquemas, representações dos meios de controlo, mediações entre o homem e a natureza. $O$ objeto técnico tornado separável pode ser reagrupado com outros objetos técnicos segundo tal esta ou aquela montagem. 0 mundo técnico fornece uma disponibilidade infinita de agrupamentos e de conexões. (...) Construir um objeto técnico é preparar uma disponibilidade (p. 245 e 246, tradução livre).

Concluamos com Gilbert Simondon: 'O objeto que resulta da invenção técnica arrasta com ele qualquer coisa do ser que a produziu, exprime desse ser o que é menos ligado a um hic et nunc» (aqui e agora)' (p. 248, tradução livre).

É bem verdade que nunca se acaba de ler um texto de Simondon e este primeiro texto que ele escreveu ainda mais do que os outros. A leitura é por vezes difícil e requer perseverança. Se o quisermos permitir tudo se esclarece com uma nova partida.

\section{BIBLIOGRAFIA}

Bardin, A. (2014). Le monde diplomatique, Décembre.

Curien, H. et al. (1992). Une pensée de lindividualisation et de la technique. Paris: Albin Michel.

Leplat, J. et Cuny, X. (1977). Introduction à la psychologie du travail. Paris: P.U.F.

Montmollin (de), M. (1984). L'intelligence de la tâche. Peter Lang: Bern.

Ombredane, A. et Faverge, J.-M. (1955). L'analyse du travail. Paris: P.U.F. 
Rabardel P. (1995). Les hommes et les technologies. Paris: Armand Colin.

Simondon, G. (1969). Du mode d'existence des objets techniques. Paris: Aubier.

Simondon, G. (2014). Sur la technique (1953-1983) Paris: P.U.F.

Wisner, A. (1985). Réflexions sur l'ergonomie. Toulouse: Octarès.

\section{NOTAS}

1. Primeira edição 1958; segunda edição 1969 utilizada para o presente texto.

\section{AUTORES}

\section{JACQUES LEPLAT}

École Pratique des Hautes Études Grupo de pesquisa e de estudo da história do trabalho e da orientação (GRESHTO) Centro de pesquisa do trabalho e do desenvolvimento (CRTD)

Conservatório Nacional das Artes e Ofícios (CNAM) Paris, France

Jacques.leplat@wanadoo.fr 